\title{
Prof. Dr. Bernhard Lembcke erhält Ernst-von-Bergmann-Plakette der Bundesärztekammer
}

\section{Langjähriges DEGUM-}

\section{Mitglied ausgezeichnet}

In Anerkennung seiner Verdienste um die ärztliche Fortbildung hat Professor Dr. Bernhard Lembcke, ehemaliger Chefarzt der Medizinischen Klinik des St. Barbara-Hospitals in Gladbeck, im März die Ernst-von-Bergmann-Plakette der Bundesärztekammer erhalten. Professor Lembcke ist seit vielen Jahren DEGUM-Mitglied und Kursleiter in der Sektion Innere Medizin und hat die Ultraschall-Ausbildung von Ärzten stets vorangetrieben. Als Wissenschaftlicher Leiter der Sonografie-Kurse der Akademie für medizini- sche Fortbildung der Ärztekammer Westfalen-Lippe und der Kassenärztlichen Vereinigung Westfalen-Lippe hat er großen Wert auf eine hochwertige ärztliche Fortund Weiterbildung gelegt. Hinzu kamen Ultraschallkurse im Rahmen der jährlichen Fort- und Weiterbildungswoche auf der Nordseeinsel Borkum, einem der größten ärztlichen Fortbildungskongresse Deutschlands. Professor Lembcke hat außerdem mehrere Lehrwerke und E-Learning-Inhalte veröffentlicht und ein Dienstleistungs- und Serviceunternehmen gegründet, das sich der Ausbildung, Beratung und dem Coaching in der Ultraschalldiagnostik widmet.

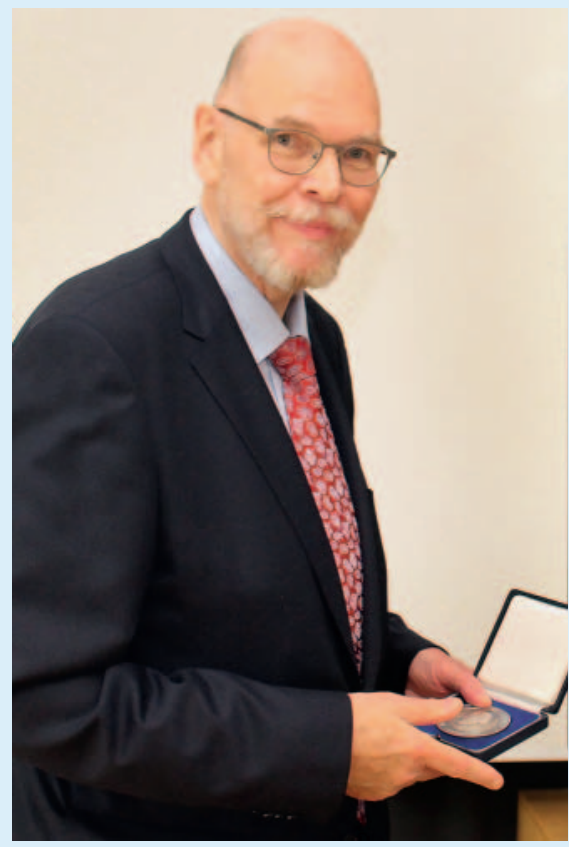

Ehrung für Prof. Lembcke. Quelle: Klaus Dercks, ÄKWL 